\title{
Advances in near-neutral salts activation of blast furnace slags
}

\author{
Susan A. Bernal $\left.\right|^{\mathrm{a}}$ \\ ${ }^{a}$ Department of Civil and Structural Engineering, The University of Sheffield, Sir Frederick Mappin Building, Sheffield S1 3JD, United Kingdom
}

Received: 19 May 2016 / Accepted: 9 June 2016 / Published online: 21 June 2016

(C) The Author(s) 2016. This article is published with open access.

\begin{abstract}
The utilisation of near-neutral salts as activators to produce alkali-activated slag cements offers several technical advantages, including reduced alkalinity of the binders, minimising the risk associated with handling of highly alkaline materials, and better workability of the fresh paste compared to that of sodium silicate-activated slag cements. Despite these evident advantages, the delayed setting and slow early-age mechanical strength development of these cements have limited their adoption and commercialisation. Recent studies have demonstrated that these limitations can be overcome by selecting slags with chemistry, which is more prone to react with near-neutral salts, or by adding mineral additives. A brief overview of the most recent advances in alkali-activation of slags using either sodium carbonate or sodium sulfate as activators is reported, highlighting the role of material design parameters in the kinetics of reaction and phase evolution of these cements, as well as the perspectives for research and development of these materials.
\end{abstract}

Keywords: Alkali-activation; Blast furnace slag; Sodium Carbonate; Sodium sulfate; Characterisation

\section{Brief overview of alkali-activated slag materials}

Alkali-activated cements are materials produced via the chemical reaction of a poorly crystalline aluminosilicate powder, and a highly alkaline solution, to form a hardened solid. These materials have been studied for more than a century, and in the past decades one of the main drivers for their development has been the potential environmental benefits associated with their production [1]. Alkali activated cements are usually produced from industrial wastes or byproducts such as blast furnace slag derived from the ironmaking industry, fly ashes from the coal combustion process, among others [2], and are now commercialised in several places around the world [3]. These materials can develop desirable properties including high mechanical strength [4], good retention of integrity when exposed to high temperatures [5] and acidic media [6], if properly formulated and cured. Significant advances have been made over the past decade in understanding alkali-activated slag materials at micro- and macroscopic scales, as discussed in recent reviews $[7,8]$, particularly for those materials produced with sodium silicate solutions as alkali-activator. The influence of formulation parameters such as chemistry of the slag $[9,10]$, type of activator [11], addition of metakaolin [12] or fly ashes [13], on the microstructural development and therefore performance of these materials have been the main focus of study in recent years. The application of advanced analytical techniques, including synchrotron X-ray diffraction [14] and X-ray fluorescence microscopy [15], along with thermodynamic modelling [16], have revealed detailed information about the chemistry and phase assemblage of these cements, allowing the development of descriptive models for the activation processes of slags (Fig. 1).

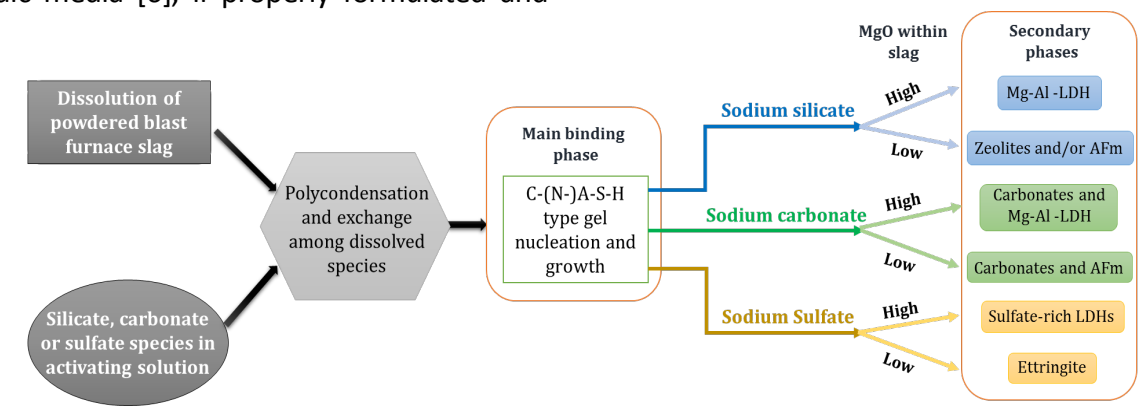

Figure 1. Simplified schematic diagram of the alkali-activation process of blast furnace slags. C-(N-)A-S-H corresponds to aluminium/sodium substituted calcium silicate hydrates, LDH describes layered double hydroxides, particularly Mg-Al-LDH phases with a hydrotalcite type structure, AFm describes hydrated calcium aluminate LDH phases with a hydrocalumite-like structure (e.g. hemicarboaluminate, monocarboaluminate or monosulfoaluminate). MgO amounts within slags can be catalogued as 'high' or 'low' based on the formation of specific reaction products, depending on the activator used. 
Despite the advantageous mechanical properties of alkaliactivated slag materials, and the high environmental benefits associated with their production, it has been demonstrated that a great part of their environmental footprint corresponds to the use of sodium silicates as the main alkaline activator $[17,18]$. Alternative sodium silicate activators produced via sodium hydroxide digestion of rice husk ashes [19, 20] or silica fume [21] have been utilised to produce alkali-activated slag cements whose microstructure is comparable to that of cements produced with commercial silicate solutions. The use of the alternative activators promoted the development of high mechanical strengths and improved performance when these cements were exposed to high temperatures $[19,20]$. These results demonstrated that the use of alternative silicate activators based on wastes such as rice husk ashes is a feasible path to replace commercial silicate solutions for the production of high performance alkali-activated slag materials.

Alkali-activation of slags is also achievable using, as sole activator, mildly alkaline solutions based on sodium carbonate $\left(\mathrm{Na}_{2} \mathrm{CO}_{3}\right)$ or sodium sulfate $\left(\mathrm{Na}_{2} \mathrm{SO}_{4}\right)$ [22, 23]. Sodium carbonate can be obtained from mined trona, and also via the Solvay process [24], while sodium sulfate is obtained from mined mirabilite, and as a by-product from $\mathrm{HCl}$ production or from processes where surplus sulfuric acid is neutralised by sodium hydroxide. The fact that these alkaline salts can be mined or obtained as by-products from different industrial activities facilitates their sourcing in different parts of the world, and at costs which are very competitive when compared to that of sodium silicates. The use of these near neutral salts has the added value of minimising potential hazards associated with handling of highly alkaline solutions, and reducing the embodied energy and environmental impact allocated to the activating solution used for producing alkali-activated cements. However, the alkali-activation of slags using these salts has received relatively little attention, as the binders produced usually take a longer time to harden than is commercially required by the construction industry, and can show delayed compressive strength development except when heat curing is applied [25].

Some of the technical challenges associated with the use of near-neutral salt activators have been overcome by incorporating into the activated slag cements minor fractions of clinker or $\mathrm{Ca}(\mathrm{OH})_{2}$ [26], limestone [27], or utilising blended activating solutions of sodium carbonate or sulfates with sodium hydroxide or silicate solutions [28], or adopting high temperature curing [1]. All these different approaches make the material harden; however, in order to move towards a more standardised way of developing alkali-activated slag binders, it is required to consider the role of the chemical and mineralogical characteristics of slags from different sources, to select the most suitable activator for a given slag.

\section{Sodium carbonate activated slag cements}

There is a good consensus that, at early times of reaction, calcium and mixed sodium-calcium carbonates are the predominant crystalline reaction products forming in sodium carbonate-activated slag cements $[11,29,30]$, instead of strength-giving phases such as calcium silicate hydrates (C-S-H). At advanced times of curing, formation of a highly cross-linked C-A-S-H type phase with a relatively low content of $\mathrm{Ca}$ in the outer product has been reported [28, 31, 32], providing strength to the hardened material. The phase assemblage developed in these cements strongly influences their pore network and mechanical strength, so that at early times of curing strength is low and a highly porous material is obtained, but, as curing progresses, the material densifies and presents a tortuous pore structure as the solid phase fraction increases, and consequently the strength rises (Fig. 2).

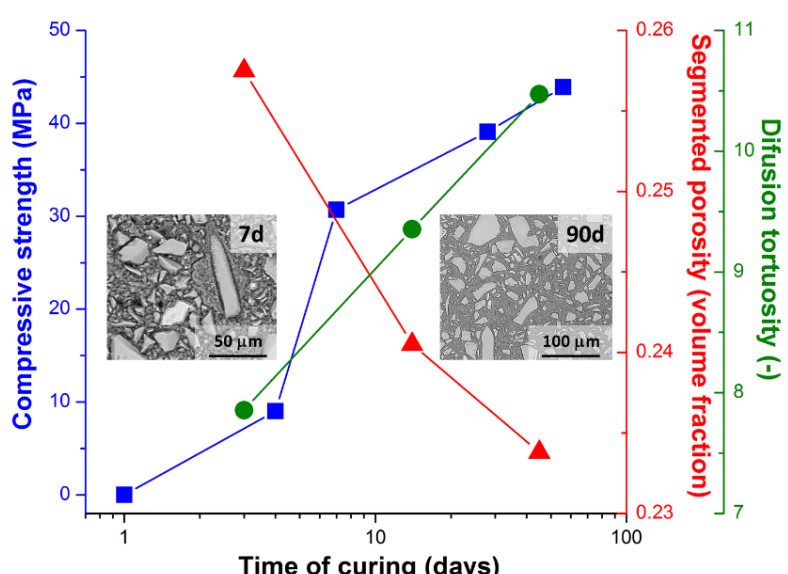

Figure 2. Compressive strength of mortars, and segmented porosity and diffusion tortuosity of 1-mm paste specimens determined by high resolution X-ray microtomography. Data from [29].

It was initially proposed [28] that the $\mathrm{Na}_{2} \mathrm{CO}_{3}$ activation reaction occurs through a cyclic hydration process where this activator supplies a buffered alkaline environment; the level of $\mathrm{CO}_{3}{ }^{2-}$ available in the system was proposed to be maintained by the continual dissolution of $\mathrm{CaCO}_{3}$, releasing $\mathrm{Ca}^{2+}$ to react with the dissolved silicate from the slag to form C-S-H type products. However, recent studies [29, 33] demonstrated that the $\mathrm{CO}_{3}{ }^{2-}$ species supplied by the activator react with the dissolved $\mathrm{Ca}^{2+}$ from the slag to form carbonate products, but as this reaction progresses, the $\mathrm{CO}_{3}{ }^{2-}$ species are exhausted. Once the $\mathrm{CO}_{3}{ }^{2-}$ is consumed, there is an increase in the alkalinity of the pore solution, and the reaction proceeds similarly to the process observed when using $\mathrm{NaOH}$ as alkaline activator. Evidence of this is the fact that similar reaction products to those forming in $\mathrm{NaOH}$ activated slag systems [34], are identified in $\mathrm{Na}_{2} \mathrm{CO}_{3}-$ activated slags at advanced curing times. This new insight has elucidated that it is feasible to develop $\mathrm{Na}_{2} \mathrm{CO}_{3}$-activated slag cements with controlled kinetics of reaction and desirable early-age performance, if the consumption of $\mathrm{CO}_{3}{ }^{2-}$ species can be controlled. 
An increased content of $\mathrm{MgO}$ within the slag accelerates the kinetics of reaction of sodium carbonate activated slag cements (Fig. 3A), and favours formation of different layered double hydroxides (LDHs) including hydrotalcite and AFm type phases (e.g. hemicarbonate $\mathrm{C}_{4} \mathrm{Ac}_{0.5} \mathrm{H}_{12}$, and/or monocarbonate $\mathrm{C}_{4} \mathrm{AcH}_{11}$ ) (Fig. 3B), depending on the composition of the slag used [33]. The LDHs forming in $\mathrm{Na}_{2} \mathrm{CO}_{3}$-activated slags can directly bind the carbonate from the activator, removing it from the pore solution. Slags with higher $\mathrm{MgO}$ content ( $>5 \mathrm{wt} . \%$ ) form larger volumes of hydrotalcite upon $\mathrm{Na}_{2} \mathrm{CO}_{3}$ activation, and react much faster than slags with less $\mathrm{MgO}$, where formation of $\mathrm{AFm}$ phases is favoured instead.

The role of the Mg-Al-containing LDHs in binding dissolved carbonates in sodium carbonate activated slag cements is somehow comparable to the binding of dissolved carbonates taking place during atmospheric carbonation of sodium-silicate activated slag binders, where it has been identified a notable reduction of carbonation depth when these cements are formulated with slags that contain sufficient $\mathrm{MgO}$, which promote extensive LDH formation [35]. It is then incorrect to assume that all $\mathrm{Na}_{2} \mathrm{CO}_{3}$-activated slags will display delayed setting, and thus limited applicability in infrastructure development, as this can be overcome by the selection of slags whose composition and mineralogy favour the formation of Mg-Al-containing LDHs.
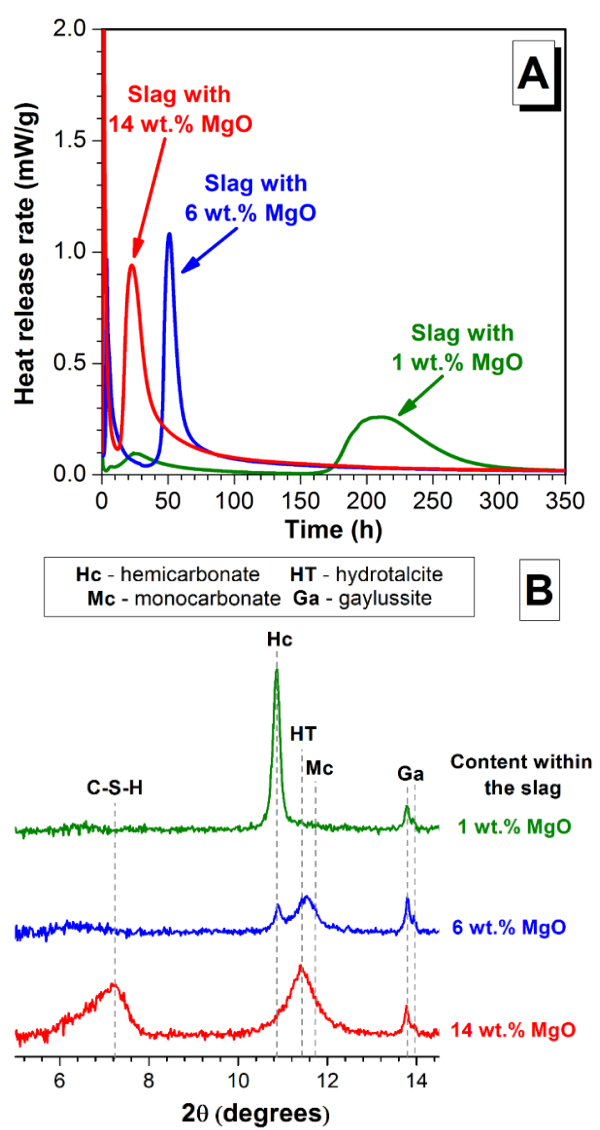

Figure 3. (A) Isothermal calorimetry curves of fresh paste, and (B) $X$ ray diffractograms of 28 days cured $\mathrm{Na}_{2} \mathrm{CO}_{3}$-activated cements, as a function of $\mathrm{MgO}$ content within the slag. Data from [33, 36].
Advances in the thermodynamic modelling of $\mathrm{Na}_{2} \mathrm{CO}_{3}$ activated slag cements have also been described in recent years [16], using the Gibbs minimisation software GEMSelektor v.3. This type of 'geochemical' modelling enables prediction of the phase assemblage and chemistry of these cements as a function of its formulation (e.g. content of $\mathrm{Na}_{2} \mathrm{CO}_{3}$ and/or slag chemical composition) and/or degree of reaction (Fig. 4). The model developed by Myers et al. [16, 37] considers the uptake of $\mathrm{Al}$ and $\mathrm{Na}$ by the main binding phase forming in these cements, a calcium aluminium silicate hydrate ( $\mathrm{C}-(\mathrm{N}-) \mathrm{A}-\mathrm{S}-\mathrm{H})$ type gel, enabling for the first time a very accurate description of the solubility relationships of this phase under the high $\mathrm{pH}$ conditions $(>12)$ and alkali concentrations prevailing during alkali activation. An updated definition of $\mathrm{Mg}-\mathrm{Al} \mathrm{LDH}$ intercalated with $\mathrm{OH}^{-}$(MA-OH-LDH) was also included in this model, and some zeolites and alkali carbonates have been added to the existing database of cement phases, which are key phases to consider when simulating alkali-activated binders. This is a valuable tool to identify the suitability of using sodium carbonate as activator for a wide range of slag chemistries and activation conditions, considering the key role of $\mathrm{Mg}-\mathrm{Al}$ $\mathrm{LDH}$ phases in controlling the kinetics of reaction of these cements.

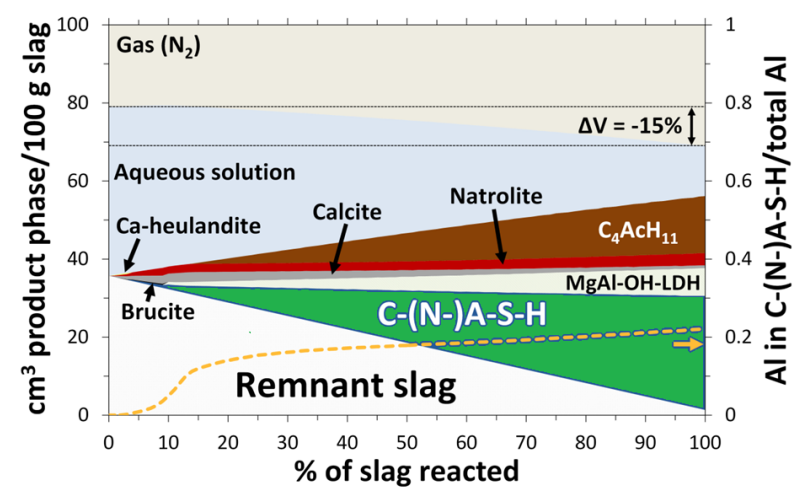

Figure 4. Simulated solid phase assemblages in a $\mathrm{Na}_{2} \mathrm{CO}_{3}$-activated slag cement. A volume decrease of $15 \%$ is shown by the horizontal dashed lines, which represents the chemical shrinkage in this system at complete reaction of the slag. The dashed orange line corresponds to the fraction of $\mathrm{Al}$ bound in $\mathrm{C}-(\mathrm{N}-) \mathrm{A}-\mathrm{S}-\mathrm{H}$ relative to the total amount of $\mathrm{Al}$ in the solid reaction products. Adapted from [16].

\section{Sodium sulfate activated slag cements}

The sulfate activation of slags typically leads to the formation of a C-A-S-H type phase with a low $\mathrm{Ca} / \mathrm{Si}$ ratio, and ettringite as the main secondary reaction product $[25,38-40]$. The setting of $\mathrm{Na}_{2} \mathrm{SO}_{4}$-activated slag cements is much faster than is identified in $\mathrm{Na}_{2} \mathrm{CO}_{3}$-activated slags [36], although these materials take a longer time to harden than sodium-silicate activated slag cements. The concentration of the $\mathrm{Na}_{2} \mathrm{SO}_{4}$ activator does not induce significant changes in the phase assemblage of these binders, but a faster slag reaction is attained when using a high activator dose [40]. These cements can develop desirable properties such as enhanced resistance to high temperatures compared with Portland 
cement systems [39] and good early compressive strength, if the fineness of the slag used is controlled [41].

Despite the advantageous properties developed by these cements, little interest has been paid to their potential applicability, and therefore there is little existing knowledge about the factors that can modify their phase assemblage and performance, including whether these materials are stable in the long term under different service conditions. These are important questions that need to be resolved, as sodium sulfate activated cements are currently attracting interest, particularly for specialised applications such as the encapsulation of radioactive metals [23] and sulfate-bearing nuclear wastes [38, 40] where long-term stability is imperative.

Recent results have demonstrated that the slag chemistry plays a key role in determining the kinetics of reaction and phase assemblage in $\mathrm{Na}_{2} \mathrm{SO}_{4}$-activated slag cements. Differences in the kinetics of reaction, particularly within the first $48 \mathrm{~h}$, were identified when using slags with different $\mathrm{MgO}$ and $\mathrm{Al}_{2} \mathrm{O}_{3}$ contents, and activated with a similar dose of $\mathrm{Na}_{2} \mathrm{SO}_{4}$, although a similar cumulative heat release was achieved after 15 days [36]. X-ray diffraction results (Fig. 5A) revealed that a high $\mathrm{Al}_{2} \mathrm{O}_{3}$ content ( 15 wt.\%) accompanied by a low $\mathrm{MgO}$ content $(\sim 1 \mathrm{wt} . \%)$ in the slag leads to the formation of monosulfoaluminate and ettringite as main reaction products. This is likely to be a consequence of the high alkalinity present in the system stabilising the monosulfoaluminate type phases rather than ettringite [42]. As the content of $\mathrm{MgO}$ within the slag increased and the $\mathrm{Al}_{2} \mathrm{O}_{3}$ reduced, ettringite was not identified as the main sulfate rich-crystalline reaction product forming in the system. Neither crystalline ettringite nor monosulfoaluminate are identified as secondary reaction products when activating slags with high $\mathrm{MgO}\left(14\right.$ wt.\%) and low $\mathrm{Al}_{2} \mathrm{O}_{3}$ (9 wt.\%) content (Fig. 5A) [36]. When using sodium silicate or sodium carbonate activators, hydrotalcite type structures have been identified as secondary reaction products when activating slags with high $\mathrm{MgO}$ contents [33, 35], but formation of crystalline hydrotalcite type phases is not observed upon sulfate activation. It is likely that the limited content of $\mathrm{Al}_{2} \mathrm{O}_{3}$ within these systems is rapidly exhausted through formation of poorly crystalline LDHs and/or AFm type phases, as identified by ${ }^{27}$ Al MAS NMR (Fig. 5B).

Similarly to the trends identified when using sodium silicate or carbonate as alkali-activators, design parameters such as the slag chemistry have a notable impact on the reaction mechanisms and structure of alkali sulfate-activated slag cements, and therefore further study is required to identify the conditions that will favour the production of high performance sulfate-activated slag cements.

\section{General remarks}

Important advances have been made in recent years in understanding the chemistry of near-neutral salt-activated slag binders. Particularly, this work has elucidated the role of the functional group accompanying the activator in controlling the kinetics of reaction, and promoting the formation of specific phase assemblages, as a function of the chemistry of the slag used. This knowledge is fundamental to the development of recommendations for the selection of the most suitable activator for a specific slag source, so that the technical and environmental benefits associated with the production of alkali-activated slag cements are maximised.

Understanding which factors control the structural and strength development of near-neutral salts activated slag cements has enabled the identification of suitable strategies to produce materials with desired properties. For instance, for $\mathrm{Na}_{2} \mathrm{CO}_{3}$-activated slag cements, the addition of minor fractions of a calcined LDH, which has the capacity to chemically bind $\mathrm{CO}_{3}{ }^{2-}$, reduced the setting times of these cements from days to hours [33], and contributed to a notable increase in the amount of chlorides that can be chemically bound in these cements [43]. The ability to manipulate the properties of these cements, when produced with a given slag source, makes them an attractive and competitive alternative to other alkali-activated cements.
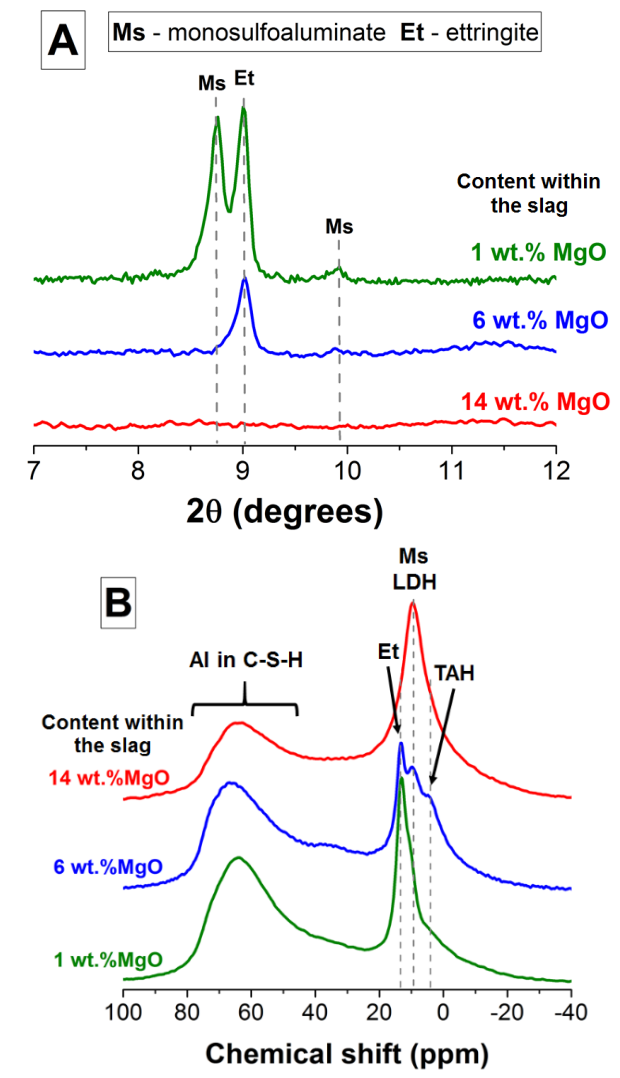

Figure 5. (A) X-ray diffractograms and (B) solid state ${ }^{27} \mathrm{Al}$ MAS NMR spectra of 180 days cured sodium sulfate activated slag cements.

Near-neutral salt-activated slag cements can develop remarkable properties, if properly formulated, without the need for high temperature curing, and depending on the slag chemistry, with or without the incorporation of mineral additions. However, there are many open questions about these materials, which need to be resolved. 
Some of these key aspects include:

- Determination of transport properties of the hardened materials obtained, considering their pore structure, chemical/drying shrinkage and consequent microcracking.

- Definition of whether these cements present comparable or improved corrosion resistance when compared to silicate-activated slag cements, due to their reduced alkalinity. For this it is required to evaluate their carbonation susceptibility and the potential of embedded steel rebars to develop corrosion processes.

- Environmental assessments over the life cycle of these cements is also needed to quantify what are the advantages in terms of embodied emissions footprint and cost that might be associated with using nearneutral salts as activators, instead of commercial sodium silicate solutions.

Some of these are areas of ongoing research, but many are still waiting to be explored, providing scope for major advancements to be made in the science of near-neutral salt-activated slag cements in the coming years.

\section{Acknowledgements}

I would like to express my gratitude to RILEM for awarding me one of the 2016 Gustavo Colonnetti medals, and to the colleagues who have supported and collaborated in my research during the years. In particular I would like to thank JL Provis (U. Sheffield), who is my beloved husband and my closest collaborator in everything I do, and R Mejia (U. del Valle, Colombia), who supported me during the early stages of my career. Also, special thanks to my former and current $\mathrm{PhD}$ students and colleagues at $\mathrm{U}$. Melbourne and $\mathrm{U}$. Sheffield, particularly JSJ van Deventer, R Myers, X Ke and I Ismail, for the knowledge we have exchanged and the important advances we have made in the area of alkaliactivated cements in recent years. I would also like to acknowledge my colleagues of RILEM TCS 224-AAM, 247-DTA and 238-SCM for the thought-provoking discussions and the great time we have shared during the meetings of these committees, as this has really contributed to my career development.

\section{References}

[1] J.L. Provis et al., Historical aspects and overview. In: J.L. Provis, J.S.J. van Deventer (Eds), Alkali-activated materials. Springer Netherlands, 2014.

[2] S.A. Bernal, E.D. Rodríguez, A.P. Kirchheim, J.L. Provis, Management and valorisation of wastes through use in producing alkali-activated cement materials. J Chem Technol Biotechnol (2016) DOI: 10.1002/jctb.4927.

[3] J.L. Provis et al., Demonstration projects and applications in building and civil Infrastructure. In: J.L. Provis, J.S.J. van Deventer (Eds), Alkaliactivated materials. Springer Netherlands, 2014.

[4] E. Rodríguez, S.A. Bernal, R. Mejía de Gutierrez, F. Puertas, Alternative concrete based on alkali-activated slag. Mater Construcc (2008) 58 (291): 53-67.

[5] S.A. Bernal, R. Mejía de Gutiérrez, F. Ruiz, H. Quiñones, J.L. Provis, High-temperature performance of mortars and concretes based on alkali-activated slag/metakaolin blends. Mater Construcc (2012) 62 (308): 471-488.
[6] S.A. Bernal, E.D. Rodríguez, R. Mejía de Gutiérrez, J.L. Provis, Performance of alkali-activated slag mortars exposed to acids. J Sustain Cement-Based Mater (2012) 1 (3): 138-151.

[7] J.L. Provis, A. Palomo, C. Shi, Advances in understanding alkaliactivated materials. Cem Concr Res (2015) 78: 110-125.

[8] C. Shi, A. Fernández-Jiménez, A. Palomo, New cements for the 21st century: The pursuit of an alternative to Portland cement. Cem Concr Res (2011) 41 (7): 750-763.

[9] S.A. Bernal et al., Gel nanostructure in alkali-activated binders based on slag and fly ash, and effects of accelerated carbonation. Cem Concr Res (2013) 53: 127-144.

[10] F. Winnefeld, M. Ben Haha, G. Le Saout, M. Costoya, S.-C. Ko, B. Lothenbach, Influence of slag composition on the hydration of alkaliactivated slags. J Sustain Cement-Based Mater (2015) 4 (2): 1-17.

[11] A. Fernández-Jiménez, F. Puertas, Setting of alkali-activated slag cement. Influence of activator nature. Adv Cem Res (2001) 13 (3): 115-121.

[12] S.A. Bernal, R. Mejía de Gutiérrez, J.L. Provis, Engineering and durability properties of concretes based on alkali-activated granulated blast furnace slag/metakaolin blends. Constr Build Mater (2012) 33: 99-108

[13] I. Ismail et al., Influence of fly ash on the water and chloride permeability of alkali-activated slag mortars and concretes. Constr Build Mater (2013) 48: 1187-1201.

[14] S.A. Bernal, J.L. Provis, V. Rose, R. Mejía de Gutiérrez, Highresolution $X$-ray diffraction and fluorescence microscopy characterization of alkali-activated slag-metakaolin binders. J Am Ceram Soc (2013) 96 (6): 1951-1957.

[15] S.A. Bernal, V. Rose, J.L. Provis, The fate of iron in blast furnace slag particles during alkali-activation. Mater Chem Phys (2014) 146 (1): 1-5.

[16] R.J. Myers, B. Lothenbach, S.A. Bernal, J.L. Provis, Thermodynamic modelling of alkali-activated slag cements. App Geochem (2015) 61: 233-247.

[17] G. Habert, J.B. d'Espinose de Lacaillerie, N. Roussel, An environmental evaluation of geopolymer based concrete production: reviewing current research trends. J Clean Prod (2011) 19 (11): 1229-1238.

[18] G. Habert, C. Ouellet-Plamondon, Recent update on the environmental impact of geopolymers. RILEM Tech Lett (2016) 1: $17-23$.

[19] S.A. Bernal, E.D. Rodríguez, R. Mejía de Gutiérrez, J.L. Provis, Performance at high temperature of alkali-activated slag pastes produced with silica fume and rice husk ash based activators. Mater Construcc (2015) 65 (318): 1-10.

[20] S.A. Bernal, E.D. Rodríguez, R. Mejía de Gutiérrez, J.L. Provis, S. Delvasto, Activation of metakaolin/slag blends using alkaline solutions based on chemically modified silica fume and rice husk ash. Waste Biomass Valor (2012) 3 (1): 99-108.

[21] V. Živica, Effectiveness of new silica fume alkali activator. Cem Concr Comp (2006) 28 (1): 21-25.

[22] J.L. Provis, S.A. Bernal, Geopolymers and related alkali-activated materials. Annu Rev Mater Res (2014) 44: 299-327.

[23] Y. Bai, N. Collier, N. Milestone, C. Yang, The potential for using slags activated with near neutral salts as immobilisation matrices for nuclear wastes containing reactive metals. J Nucl Mater (2011) 413 (3): 183-192.

[24] G. Steinhauser, Cleaner production in the Solvay process: general strategies and recent developments. J Clean Prod (2008) 16 (7): 833841.

[25] S.A. Bernal et al., Binder chemistry-high-calcium alkali-activated materials. In: J.L. Provis, J.S.J. van Deventer (Eds), Alkali-activated materials. Springer Netherlands, 2014.

[26] E. Douglas, J. Brandstetr, A preliminary study on the alkali activation of ground granulated blast-furnace slag. Cem Concr Res (1990) 20 (5): 746-756.

[27] A.R. Sakulich, S. Miller, M.W. Barsoum, Chemical and microstructural characterization of 20-month-old alkali-activated slag cements. J Am Ceram Soc (2010) 93 (6): 1741-1748.

[28] H. Xu, J.L. Provis, J.S.J. van Deventer, P.V. Krivenko, Characterization of aged slag concretes. ACI Mater J (2008) 105 (2): 131-139.

[29] S.A. Bernal, J.L. Provis, R.J. Myers, R. San Nicolas, J.S.J. van Deventer, Role of carbonates in the chemical evolution of sodium carbonateactivated slag binders. Mater Struct (2015) 48: 517-529.

[30] M. Kovtun, E.P. Kearsley, J. Shekhovtsova, Chemical acceleration of a neutral granulated blast-furnace slag activated by sodium carbonate. Cem Concr Res (2015) 72: 1-9. 
[31] A. Fernández-Jiménez, F. Puertas, I. Sobrados, J. Sanz, Structure of calcium silicate hydrates formed in alkaline-activated slag: Influence of the type of alkaline activator. J Am Ceram Soc (2003) 86 (8): 13891394.

[32] A.J. Moseson, Design and Implementation of Alkali Activated Cement for Sustainable Development, PhD Thesis, Philadelphia, Drexel University, 2011.

[33] X. Ke, S.A. Bernal, J.L. Provis, Controlling the kinetics of reaction of sodium carbonate-activated slag cements using calcined layered double hydroxides. Cem Concr Res (2015) 81: 24-37.

[34] J. Escalante-García, A.F. Fuentes, A. Gorokhovsky, P.E. Fraire-Luna, G. Mendoza-Suarez, Hydration products and reactivity of blastfurnace slag activated by various alkalis. J Am Ceram Soc (2003) 86 (12): 2148-2153.

[35] S.A. Bernal et al., MgO content of slag controls phase evolution and structural changes induced by accelerated carbonation in alkaliactivated binders. Cem Concr Res (2014) 57: 33-43.

[36] S.A. Bernal, X. Ke, J.L. Provis, Activation of slags using near-neutral salts: The importance of slag chemistry. The 14th International Congress on Chemistry of Cement. Beijing, China, 2015.

[37] R.J. Myers, S.A. Bernal, J.L. Provis, A thermodynamic model for C(N-)A-S-H gel: CNASH_ss. Derivation and validation. Cem Concr Res (2014) 66: 27-47.

[38] N. Mobasher, S.A. Bernal, O.H. Hussain, D.C. Apperley, H. Kinoshita, J.L. Provis, Characterisation of $\mathrm{Ba}(\mathrm{OH})_{2}-\mathrm{Na}_{2} \mathrm{SO}_{4}$-blast furnace slag cement-like composites for the immobilisation of sulphate bearing nuclear wastes. Cem Concr Res (2014) 66: 64-74.

[39] A.M. Rashad, Y. Bai, P.A.M. Basheer, N.C. Collier, N.B. Milestone, Chemical and mechanical stability of sodium sulfate activated slag after exposure to elevated temperature. Cem Concr Res (2012) 42 (2): 333-343.

[40] N. Mobasher, B. S.A., P. J.L, Structural evolution of an alkali sulphate activated slag cement. J Nucl Mater (2016) 468: 97-104.

[41] A.M. Rashad, Y. Bai, P.A.M. Basheer, N.B. Milestone, N.C. Collier, Hydration and properties of sodium sulfate activated slag. Cem Concr Comp (2013) 37 (0): 20-29.

[42] B.A. Clark, P.W. Brown, The formation of calcium sulfoaluminate hydrate compounds Part II. Cem Concr Res (2000) 30: 233 - 240.

[43] X. Ke, S.A. Bernal, J.L. Provis, The influence of calcined layered double hydroxides on chloride binding in alkali-activated slag cement. 35th Cement and Concrete Science Conference. Aberdeen, Scotland, 2015. 